\title{
From Tiny Microalgae to Huge Biorefineries
}

\section{Luisa Gouveia*}

LNEG - National Laboratory of Energy and Geology, Bioenergy Unit, Portugal

\begin{abstract}
Microalgae are an emerging research field due to their high potential as a source of several biofuels in addition to the fact that they have a high-nutritional value and contain compounds that have health benefits. They are also highly used for water stream bioremediation and carbon dioxide mitigation. Therefore, the tiny microalgae could lead to a huge source of compounds and products, giving a good example of a real biorefinery approach.
\end{abstract}

This work shows and presents examples of experimental microalgae-based biorefineries grown in an autotrophic mode at a laboratory scale.

\section{Keywords: Microalgae; Biorefinery}

\section{Introduction}

Biofuel and bioproduct production from microalgae have several advantages when compared to the $1^{\text {st }}$ and $2^{\text {nd }}$ biofuel generation having: high areal productivity, minimal competition with conventional agriculture, environmental benefits by recycling nutrients ( $\mathrm{N}$ and $\mathrm{P}$ ) from waste waters and mitigating carbon dioxide from air emissions. In addition, all components of microalgae can be separated and transformed into different valuable products. The high metabolic versatility of microalgae and cyanobacteria metabolisms, offer interesting applications in several fields such as nutrition (human and animal), nutraceuticals, therapeutic products, fertilizers, plastics, isoprene, biofuels and environment (such as water stream bioremediation and carbon dioxide mitigation).

The high content of antioxidants and pigments (carotenoids such as fucoxanthin, lutein, betacarotene and/or astaxanthin and phycobilliproteins) and the presence of long-chain Polyunsaturated Fatty Acids (PUFAs) and proteins (essential amino acids methionine, threonine and tryptophan), makes microalgae an excellent source of nutritional compounds. Coextraction of other high-value products (PUFAs, such as Eicosapentaenoic Acid (EPA), Docosahexaenoic Acid (DHA), and Arachidonic Acid (AA)) will also be evaluated since these compounds may enhance the nutritional or nutraceutical value of the microalgal oil.

Microalgae have also been screened for new pharmaceutical compounds with biological activity, such as antibiotics, antiviral, anticancer, enzyme inhibitory agents and other therapeutic applications. They have been reported to potentially prevent or reduce the impact of several lifestyle-related diseases [1-3] with antimicrobial (antibacterial, antifungal, antiprotozoal) and antiviral (including anti-HIV) functions and they also have cytotoxic, antibiotic, and anti-tumour properties as well as having biomodulatory effects such as immunosuppressive and anti-inflammatory roles [4,5]. Chlorella has also been used against infant malnutrition and neurosis [6], as well as being a food additive. Furthermore, algae are believed to have a positive effect on the reduction of cardio-circulatory and coronary diseases, atherosclerosis, gastric ulcers, wounds, constipation, anaemia, hypertension, and diabetes [6,7].

The microalgae compounds, such as carotenoids have also been associated and claimed to reduce the risk of: (1) certain cancers [811], (2) cardiovascular diseases [12,13], (3) macular degeneration and cataract formation $[14,15]$ and possibly may have an effect on the immune system and may influence chronic diseases [16,17].

Besides nutritional, nutraceutical and therapeutic compounds, microalgae can also synthesize polysaccharides that can be used as an emulsion stabilizer or as biofloculants and polyhydroxyalkanoate, which are linear polyesters used in the production of bioplastics. Microalgae biomass has been demonstrated to improve the physical and thermal properties of plastic by replacing up to $25 \%$ of polymers, which increases the biodegradability of the final bioplastic. Microalgae can also produce isoprene, which is a key intermediate compound for the production of synthetic rubber and adhesives, including car and truck tires. It is also an important polymer building block for the chemical industry, such as for a wide variety of elastomers used in surgical gloves, rubber bands, golf balls, and shoes [18].

Furthermore, the aminoacids produced by microalgae can be used as biofertilizers and therefore assist higher plant growth. Aminoacid based fertilization supplies plants with the necessary elements to develop their structures by adding nutrients through the natural processes of nitrogen fixation, solubilizing phosphorus, and stimulating plant growth through the synthesis of growth-promoting substances [19-21]. Bio-fertilizers provide eco-friendly organic agroinput and are more cost-effective than chemical fertilizers.

Finally, regarding biofuels, they can be obtained from the microalgae biomass leftovers after the extraction of added-value compounds. According to the composition of the "waste" biomass, it can be used for the production of liquid biofuels (bioethanol, biodiesel, biobutano and bio-oil) $[22,23]$ or gaseous biofuels (biomethane, biohydrogen, syngas etc.) [24-26]. The technology used to produce biofuels efficiently is not yet established, thus different biological and thermochemical processes still need to be studied and improved.

*Corresponding author: Luisa Gouveia, LNEG - National Laboratory of Energy and Geology, Bioenergy Unit, Estrada do Paço do Lumiar 22 - 1649-038, Lisbon, Portugal, Tel: 0035121 0924600; E-mail: luisa.gouveia@Ineg.pt

Received Februay 12, 2014; Accepted March 24, 2014; Published March 26 , 2014

Citation: Gouveia L (2014) From Tiny Microalgae to Huge Biorefineries Oceanography 2: 120. doi:10.4172/2332-2632.1000120

Copyright: $\odot 2014$ Gouveia L. This is an open-access article distributed under the terms of the Creative Commons Attribution License, which permits unrestricted use, distribution, and reproduction in any medium, provided the original author and source are credited. 
Unfortunately, the economic viability of algae-based biofuels is still unfeasible. However, the high metabolic versatility of microalgae and cyanobacteria metabolisms allow the production of the several mentioned non-fuel products, which have a very high value and could play a major role in turning economic and energy balances more favorable. This versatility and huge potential of tiny microalgae could support a microalgae-based biorefinery and microalgae-based bioeconomy opening up vast opportunities in the global algae business.

The microalgae could play an important response to the worldwide biofuel demand, together with the production of high value-added products and assisting some other environmental issues such as water stream bioremediation and carbon dioxide mitigation.

Only the co-production of high added value products and environmental benefits could eventually off-set the high production costs of mass microalgae cultivation and support a microalgae-based bioeconomy. In fact, a microalgae-based biorefinery should integrate several processes and related industries, such as food, feed, energy, pharmaceutical, cosmetic, and chemical. Such an approach, in addition to the biomass, will take advantage of the various products synthesized by the microalgae. This adds value to the whole process which has a minimal environmental impact by recycling the nutrients and water, and by mitigating the $\mathrm{CO}_{2}$ from the flue gases (Figure 1).

This review highlights the potential of the tiny autotrophic microalgae for the production of several products in an experimental (lab scale) Biorefinery. The production contains biofuel(s) and other high value-added compounds which could be used for different applications and markets.

\section{From (Tiny) Microalgae to (Huge) Biorefineries}

The main bottleneck of the biorefinery approach is to separate the different fractions without damaging one or more of the product fractions. There is a need for mild, inexpensive and low energy consumption separation techniques to overcome these bottlenecks $[27,28]$. They should also be applicable for a variety of end products which have a sufficient quality but are also available in large quantities $[29,30]$.

Some of the biorefinery techniques appropriate for metabolite separation and extraction are ionic liquids or surfactants $[28,31]$. These techniques are relatively new and should therefore be studied thoroughly before commercial use will be possible.

\section{Nannochloropsis sp. biorefinery}

Nobre et al. [31] used Nannochloropsis sp. microalga and developed a Biorefinery with the extraction of carotenoids and fatty acids (mainly EPA) for food and the feed industry as well as lipids for biodiesel production. The biomass composition is present in Table 1.

The fractionated recovery of the different compounds was done by Supercritical Extraction using $\mathrm{CO}_{2}$ and ethanol as an entrainer. From the biomass leftovers and using Enterobacter aerogeneses through dark fermentation, $\mathrm{bioH}_{2}$ was also produced (Figure 2), yielding a maximum of $60.6 \mathrm{~mL} \mathrm{H}_{2} / \mathrm{g}$ alga [31].

The energy consumption and $\mathrm{CO}_{2}$ emissions emitted during the whole process (microalgae cultivation, harvesting, dewatering, milling, extraction and leftover biomass fermentation), as well as the economic factors were evaluated [25]. The authors showed five pathways and two biorefineries which were analysed (Figure 3):
Path \# 1) Oil extraction by soxhlet (oil SE);

Path \#2) Oil and pigment extraction and fractionation through Supercritical Fluid Extraction (oil and pigment SFE);

Path \#3) Hydrogen production through dark fermentation of the leftover biomass after soxhlet extraction ( $\mathrm{bioH}_{2}$ via SE);

Path \#4) Hydrogen production by dark fermentation from the leftover biomass after Supercritical Fluid extraction ( $\mathrm{bioH}_{2}$ via SFE);

Path \#5) Hydrogen production from the whole biomass through dark fermentation ( $\mathrm{bioH}_{2}$ using the whole biomass).

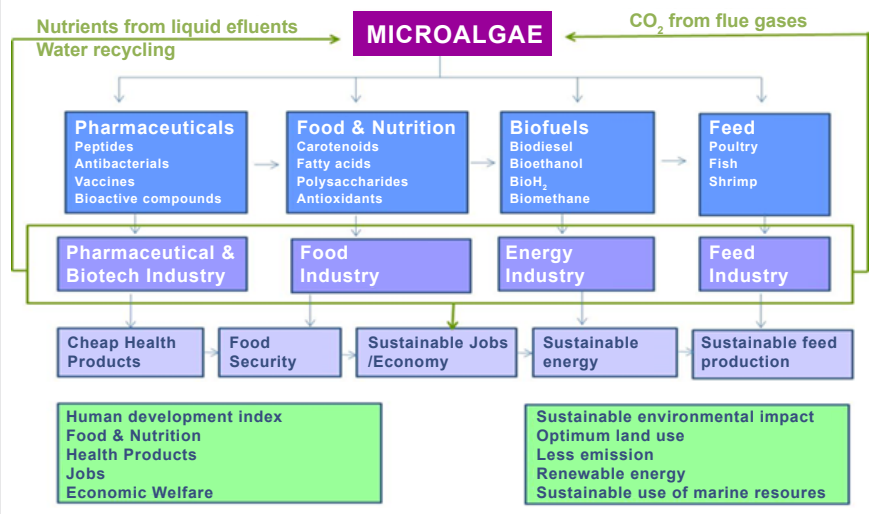

Figure 1: Example of a microalgae based biorefinery and how it integrates several related industries (adapted from Subhadra [46]).

\begin{tabular}{|c|c|}
\hline Composition & (\%) \\
\hline Crude fat & 41 \\
\hline Total sugars & 17 \\
\hline Total minerals & 13 \\
\hline Others & 29 \\
\hline
\end{tabular}

Table 1: Nannochloropsis sp. composition.

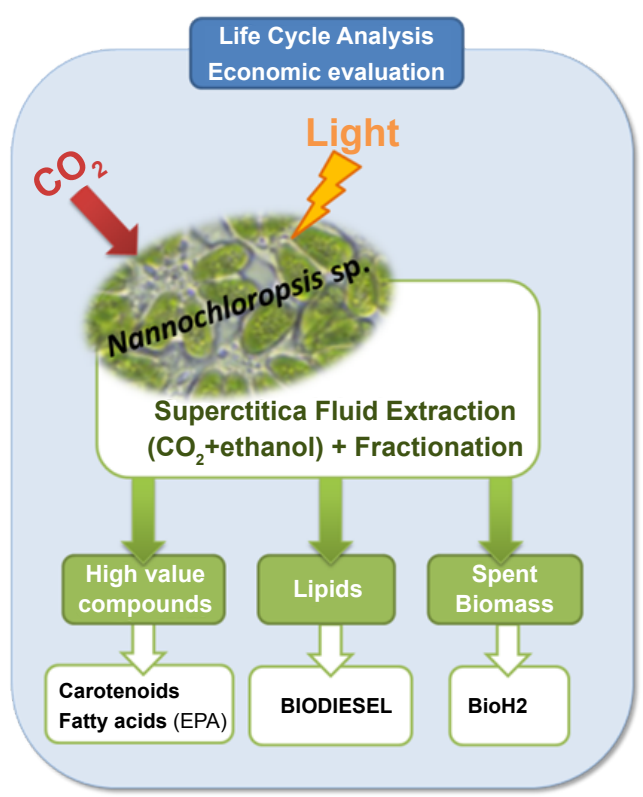

Figure 2: Nannochloropsis sp. biorefinery. 


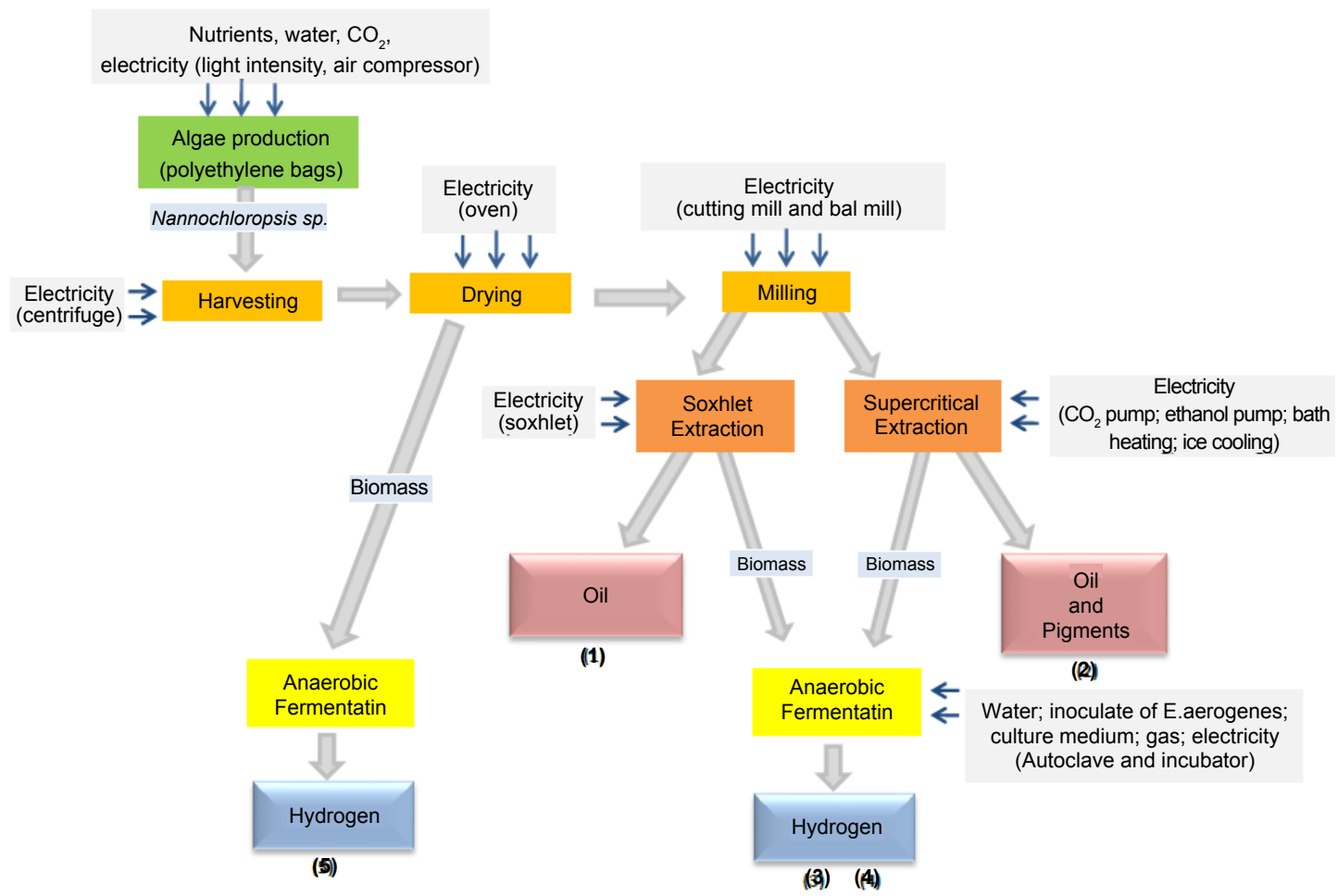

Figure 3: Nannochloropsis sp. biorefinery (including all steps, material and energy, and different pathways) to the production of oil, pigments and bioHydrogen) (adapted from Ferreira, et al. [50]).

Where path \#1 and path \#3 are the Biorefinery 1 , path \#2 and path $\# 4$ are the Biorefinery 2 and path $\# 5$ is the direct bioH $_{2}$ production.

The analysis of pathways \#1, \#2 and \#5 considers a system boundary from the Nannochloropsis sp. microalgal culture to the final product output (oil, pigments, or bioH $_{2}$, respectively). For pathways \#3 and $\# 4$, the bioH $\mathrm{H}_{2}$ production from the leftover biomass from SE and SFE respectively was evaluated.

The authors concluded that the oil production pathway by SE shows the lowest energy consumption, 176-244 MJ/MJ $\mathrm{prod}_{\text {, }}$ and $\mathrm{CO}_{2}$ emissions, $13-15 \mathrm{~kg} \mathrm{CO}_{2} / \mathrm{MJ}_{\text {prod }}$.

However, economically the most favourable biorefinery was the one producing oil, pigments and $\mathrm{H}_{2}$ via Supercritical Fluid Extraction (SFE).

From the net energy balance and the $\mathrm{CO}_{2}$ emission analysis, Biorefinery 1 (biodiesel $\mathrm{SE}+\mathrm{bioH}_{2}$ ) presented the better results. Biorefinery 2 (biodiesel SFE $+\mathrm{bioH}_{2}$ ) showed results in the same range of those in Biorefinery 1. However, the use of SFE produced high-value pigments in addition to the fact that it is a clean technology which does not use toxic organic solvents.

Therefore, Biorefinery 2 was the best in terms of energy/ $\mathrm{CO}_{2} /$ and it being the most economically advantageous solution.

\section{Anabaena sp. biorefinery}

The experimental biohydrogen production by photoautrotophic cyanobacterium Anabaena sp. was studied by Marques et al. [24]. Hydrogen production from the Anabaena biomass leftovers was also achieved by fermentation through the Enterobacter aerogenes bacteria and was reported by Ferreira et al. [32] (Figure 4).
Different culture conditions and gas atmospheres were tested in order to maximize the autotrophic bioH $\mathrm{H}_{2}$ yield versus the energy consumption and $\mathrm{CO}_{2}$ emissions. The authors stated that the best conditions included an $\mathrm{Ar}+\mathrm{CO}_{2}+20 \% \mathrm{~N}_{2}$ gas atmosphere and medium light intensity (384 W) [32]. The yielded $\mathrm{H}_{2}$ could be increased using the biomass leftovers through a fermentative process; however this would mean higher energy consumption as well as an increase in $\mathrm{CO}_{2}$ emissions.

\section{Chlorella vulgaris biorefineries}

Quite a few reported works describe biorefineries from Chlorella vulgaris and these are stated below:

Cv1 - An integrating process for lipid recovery from the biomass of Chlorella vulgaris and methane production from the remaining biomass (after lipid extraction) was worked on by Collet et al. [33]. The authors demonstrated that, in terms of Life Cycle Assessment (LCA), the methane from algae (algal methane) is the worst case, compared to algal biodiesel and diesel, in terms of abiotic depletion, ionizing radiation, human toxicity, and possible global warming. These negative results are mainly due to a strong demand for electricity. For the land use category, algal biodiesel also had a lesser impact compared to algal methane. However, algal methane is a much better option in terms of acidification and eutrophication.

Cv2 - Another work concerning the simultaneous production of biodiesel and methane in a biorefinery concept was done by Ehimen et al. [34]. The authors obtained biodiesel from a direct transesterification on the Chlorella microalgal biomass, and from the biomass residues they obtained methane through anaerobic digestion. For a temperature of $40^{\circ} \mathrm{C}$ and a C/N mass ratio of 8.53 , a maximum methane concentration 
of $69 \%$ (v/v) with a specific yield of $0.308 \mathrm{~m}^{3} \mathrm{CH}_{4} / \mathrm{kg}$ VS was obtained. However, in this work the biodiesel yield was not reported.

Cv3 - In another work, the Chlorella vulgaris biorefinery approach was studied by Gouveia, et al. [35] and it included a Photosynthetic Algal Microbial Fuel Cell (PAMFC), where the microalga Chlorella vulgaris are present in the cathode compartment (Figure 5). The study demonstrated the simultaneous production of bioelectricity and added-value pigments, with possible wastewater treatment. The authors proved that the light intensity increases the PAMFC power and augments the carotenogenesis process in the cathode compartment. The maximum power produced was $62.7 \mathrm{~mW} / \mathrm{m}^{2}$ with a light intensity of $96 \mu \mathrm{E} /\left(\mathrm{m}^{2} . \mathrm{s}\right)$.

Cv4 - A bioethanol-biodiesel-microbial fuel cell was reported by Powel and Hill [36] and basically consisted in an integration of photosynthetic Chlorella vulgaris (in the cathode) that captured $\mathrm{CO}_{2}$ emitted by yeast (in the anode) fermenters, creating a microbial fuel cell. The study demonstrated the possibility of electrical power generation and oil for biodiesel, in a bioethanol production facility. The remaining biomass after oil extraction could also be used in animal feed supplement [36].

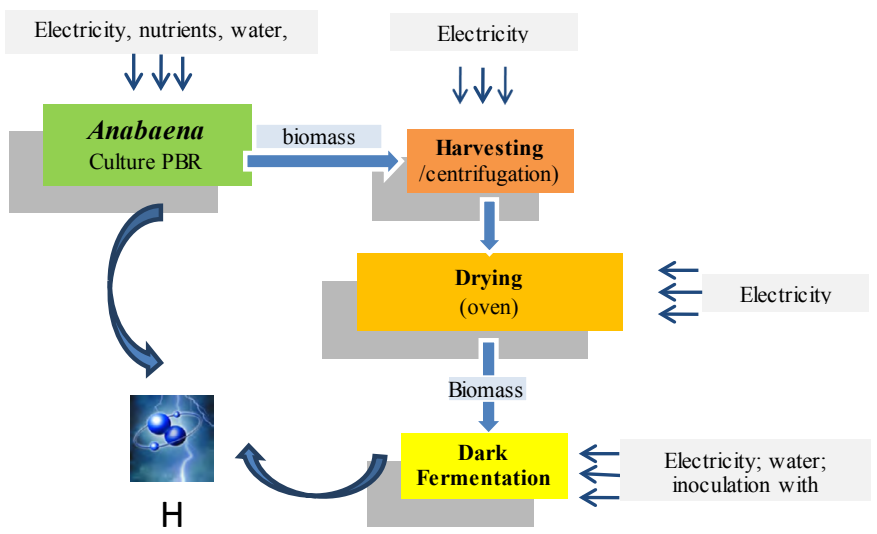

Figure 4: Anabaena sp. biorefinery (including both $\mathrm{H}_{2}$ production: autotrophically and by dark fermentation (through Enterobacter aerogenes) (adapted from Ferreira, et al. [32]).

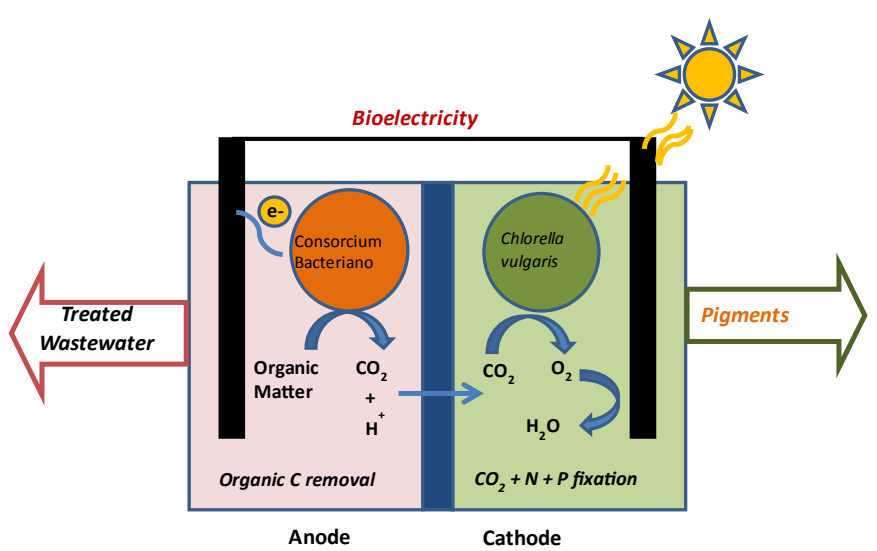

Figure 5: Chlorella vulgaris biorefinery (Photosynthetic Algal Microbial Fuel Cell) (adapted from da Silva TL, et al. [30]).

\section{Chlorella protothecoids biorefinery}

The biorefinery stated by Campenni et al. [37] used Chlorella protothecoides as a source of lipids and carotenoids, it was grown autotrophically and with nitrogen deprivation and the addition of a 20 $\mathrm{g} / \mathrm{l} \mathrm{NaCl}$ solution (Figure 6)

The total carotenoid content was $0.8 \%(\mathrm{w} / \mathrm{w})$ (canthaxanthin (23.3\%), echinenone (14.7\%), free astaxanthin (7.1\%) and lutein/ zeaxanthin $(4.1 \%)$ ) which can be used for food applications. Furthermore, the total lipid content reached $43.4 \%$ (w/w), with a fatty acid composition of C18:1 (33.6\%), C16:0 (23.3\%), C18:2 (11.5\%), and C18:3 (less than 12\%), which is needed to fulfil the biodiesel EN 14214 quality specifications [38] and can be used for the biofuel (biodiesel) industry.

The leftover biomass is still available for hydrogen or bioethanol production in a biorefinery approach, as the residue still contains sugar taking advantage of all the C. protothecoids gross composition.

\section{Chlorella reinhardtii biorefinery}

The production of biohydrogen and the consequent biogas (methane) production by anaerobic fermentation of the residue of Chlorella reinhardtii biomass were achieved by Mussgnug et al. [39].

The authors reported that using the biomass, after the hydrogen production cycle instead of using the fresh biomass, would increase the biogas production by $123 \%$. The authors attributed these results to the storage compounds, such as starch and lipids with a high fermentative potential which is the key in the microalgae-based integrated process and could be used for more value-added applications.

\section{Dunaliella salina biorefinery}

Sialve et al. [40] attested the production of methane from the leftover biomass of Dunaliella salina after the oil extraction to make biodiesel. The authors found a much higher yield (around 50\%) for a shorter hydraulic retention time (HRT, 18 days), than the corresponding values reported by Collet et al. [33] using the Chlorella vulgaris biomass.

\section{Dunaliella tertiolecta biorefinery}

The chemoenzymatic saccharification and bioethanol fermentation of the residual biomass of Dunaliella tertiolecta after lipid extraction (for biodiesel production purposes) were investigated by Kim et al. [41]. The bioethanol was produced from the enzymatic hydrolysates without pretreatment by $S$. cerevisiae, resulting in yields of $0.14 \mathrm{~g}$ ethanol/g residual biomass and $0.44 \mathrm{~g}$ ethanol/g glucose produced from the residual biomass.

According to these authors, the residual biomass generated during microalgal biodiesel production, could be used for bioethanol production in order to improve the economic feasibility of a microalgaebased integrated process.

\section{Arthrospira (Spirulina) biorefinery}

Olguin [42] highlighted that the biorefinery strategy offers new opportunities for a cost-effective and competitive production of biofuels along with nonfuel compounds. The author studied an integrated system where the production of biogas, biodiesel, hydrogen and other valuable products (e.g. PUFAs, phycocyanin, and fish feed) could be possible. 


\section{Spirogyra sp. biorefinery}

Pacheco et al. [43] pointed a biorefinery from Spirogyra sp., a sugar-rich microalga, for bioH $_{2}$ production as well as pigments (Figure 7). The economic and life cycle analysis of the whole process, allowed the authors to conclude that it is crucial to increase the sugar content of the microalgae to increase the $\mathrm{bioH}_{2}$ yield. Furthermore, it is important to reduce the centrifugation needs and use alternative methods for pigment extraction other than using acetone solvents. The electrocoagulation and solar drying were used for harvesting and dewatering, respectively, and were able to reduce energy requirements by $90 \%$. Overall, centrifugation of the microalgal biomass and heating of the fermentation vessel are still major energy consumers and $\mathrm{CO}_{2}$ contributors to this process. Pigment production is necessary to improve the economic benefits of the biorefinery, but it is mandatory to reduce its extraction energy requirements that are demanding $62 \%$ of the overall energy.

Mostafa et al. [44] evaluated the growth and lipid, glycerol, and carotenoid content of nine microalgae species (green and blue green microalgae) grown in domestic wastewater obtained from the Zenein Wastewater Treatment Plant in the Giza governorate in Egypt (Figure 8). The authors cultivated the different species under different conditions, such as without treatment after sterilization, with nutrients and sterilization, and with nutrients without sterilization, at $25 \pm 1^{\circ} \mathrm{C}$, under continuous shaking $(150 \mathrm{rpm})$ and illumination (2,000 lx), for 15 days. The highest biodiesel production from algal biomass cultivated in wastewater was obtained by Nostoc humifusum
$(11.80 \%)$ when cultivated in wastewater without treatment and the lowest $(3.8 \%)$ was recorded by Oscillatoria sp. when cultivated on the sterilized domestic wastewater. The authors concluded that cultivating microalgae on domestic wastewater, combines nutrient removal and algal lipid production which has a high potential in terms of biodiesel feedstock. This methodology is suitable and non-expensive compared to the conventional cultivation methods for sustainable biodiesel and glycerol.

According to Subhadra and Edwards [45] (Figure 9), an integrated Renewable Energy Park (IREP) approach can be envisaged by combining different renewable energy industries, in resource-specific regions, for synergetic electricity and liquid biofuel production, with zero net carbon emissions. Choosing the appropriate location, an IREP design, combining a wind power plant with solar panels and algal growth facilities to harness additional solar energy, could greatly optimize land. Biorefineries configured within these IREPs can produce about 50 million gallons of biofuel per year, providing many other value-added co-products and having almost no environmental impact [46] (Figure 9).

Clarens et al. [47] suggested that the results from algae-to-energy systems can be either net energy positive or negative depending on the specific combination of cultivation and conversion processes used addressed the shortcoming "well-to-wheel", including the conversion of each biomass into transportation energy sources. The algal conversion pathway resulted in a combination of biodiesel and bioelectricity production for transportation, evaluated by Vehicle

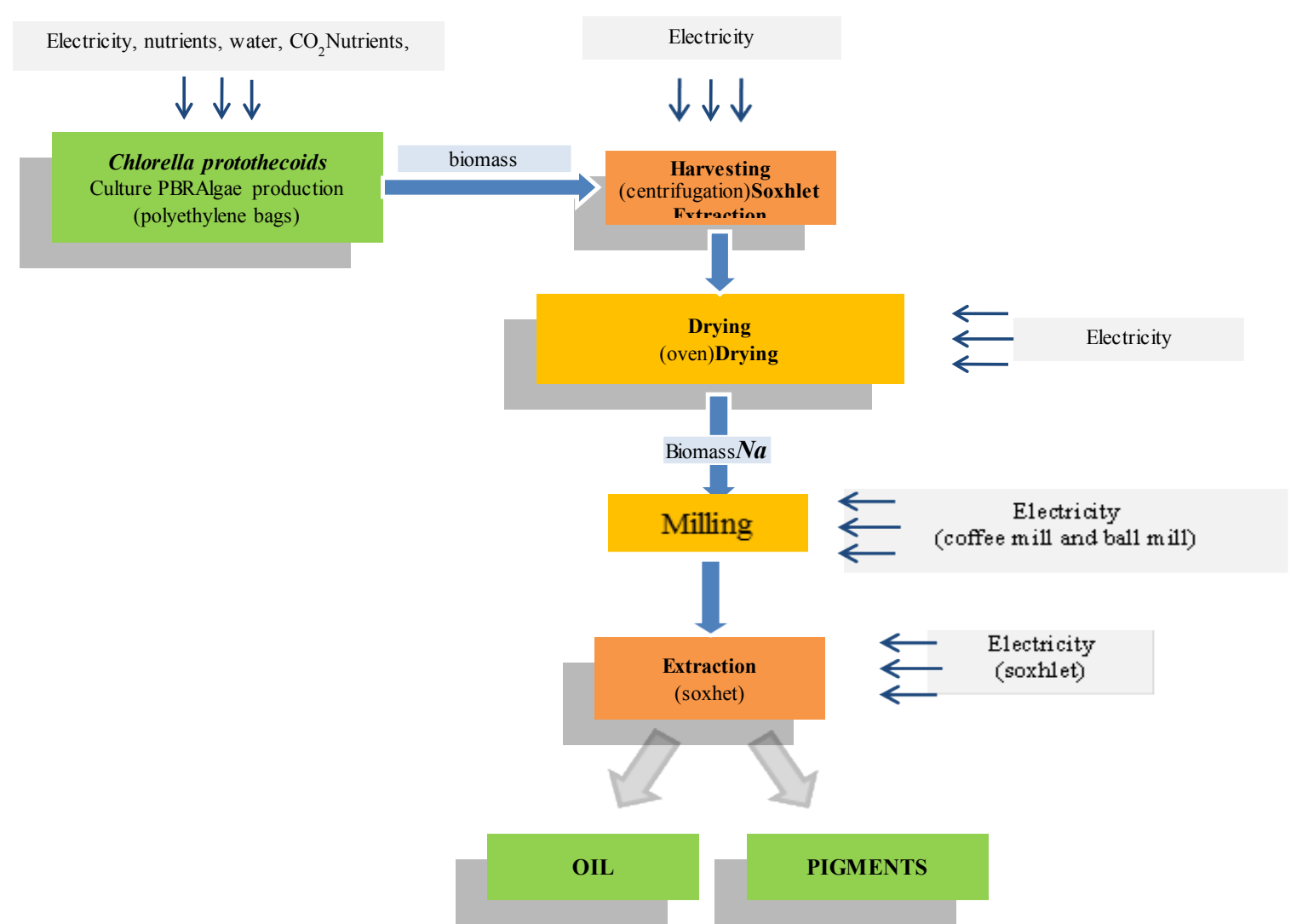

Figure 6: Chlorella protothecoids biorefinery (adapted from Campenni', et al. [37]). 


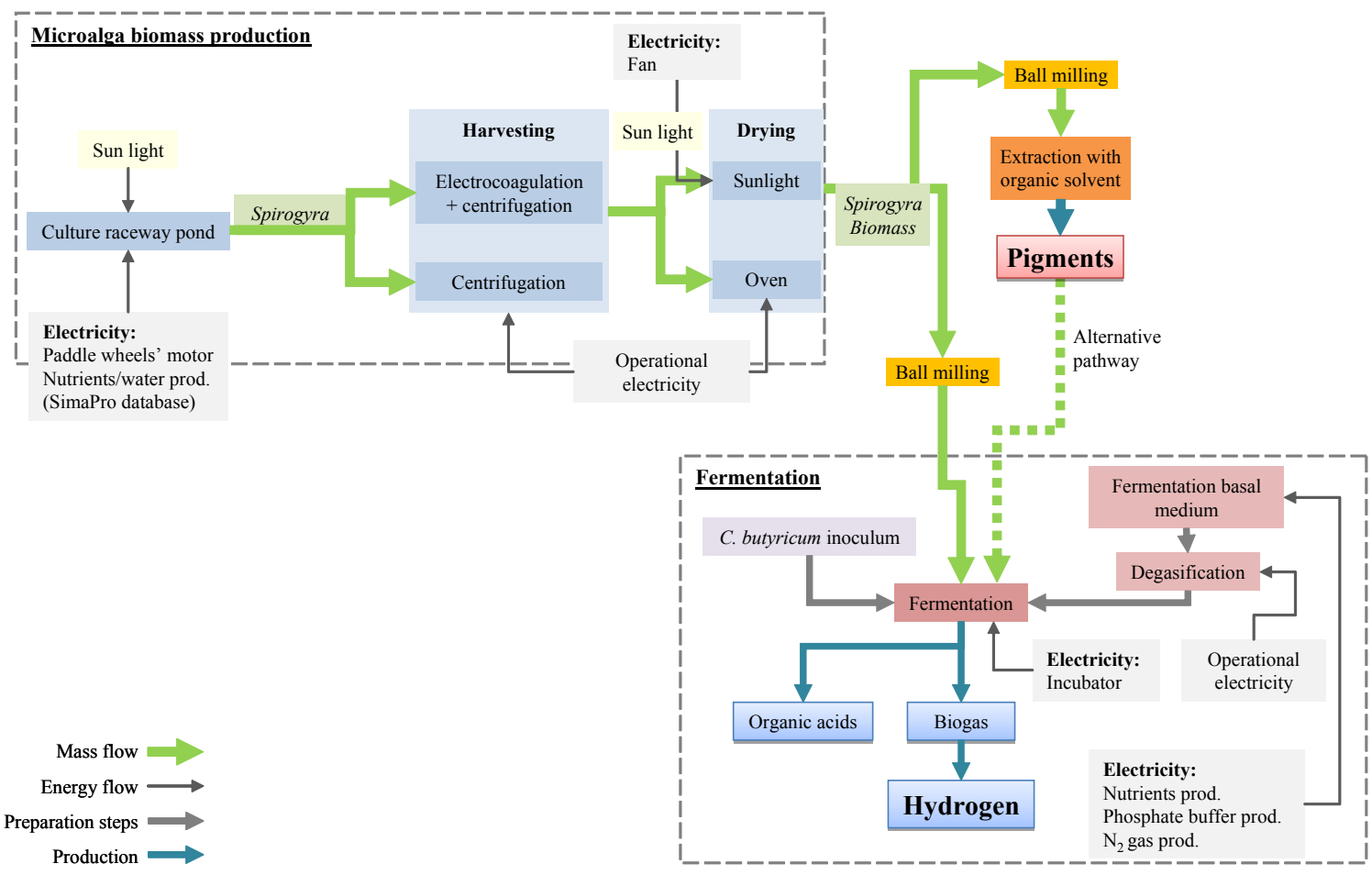

Figure 7: Spirogyra sp. biorefinery (adapted from Pacheco, et al. [43])

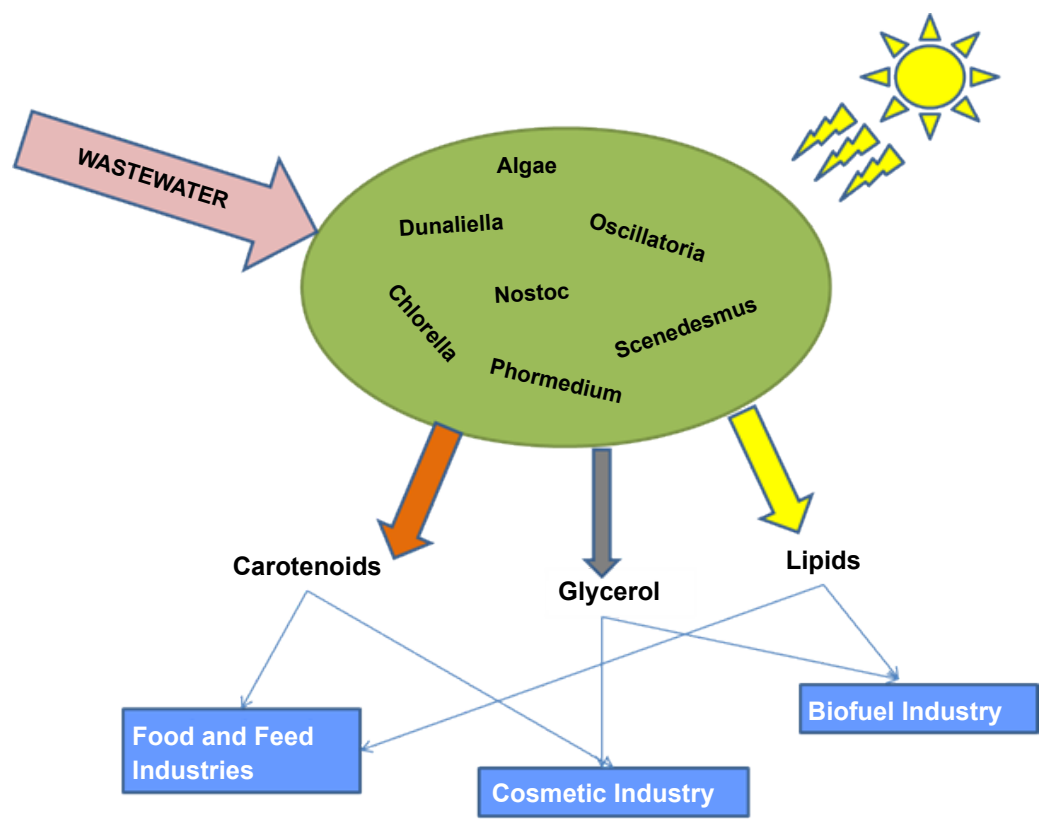

Figure 8: Biorefinery from several microalgae using w astew ater w ith lipid, carotenoid and glycerol production (adapted from Mostafa, et al. [44]).

Kilometers Traveled (VKT) per hectare. In this study, it was assumed that bioelectricity and biodiesel are used in commercially available Battery Electric Vehicles (BEVs) and Internal Combustion Vehicles (ICVs), respectively. The authors depicted four pathways:

A. Methane-derived bioelectricity from the bulk algae biomass by anaerobic digestion
B. Biodiesel from the algae lipids and methane-derived bioelectricity from the residual biomass by anaerobic digestion

C. Biodiesel from the algae lipids and bioelectricity from the residual biomass by direct combustion

D. Bioelectricity from the bulk algae biomass by direct combustion 


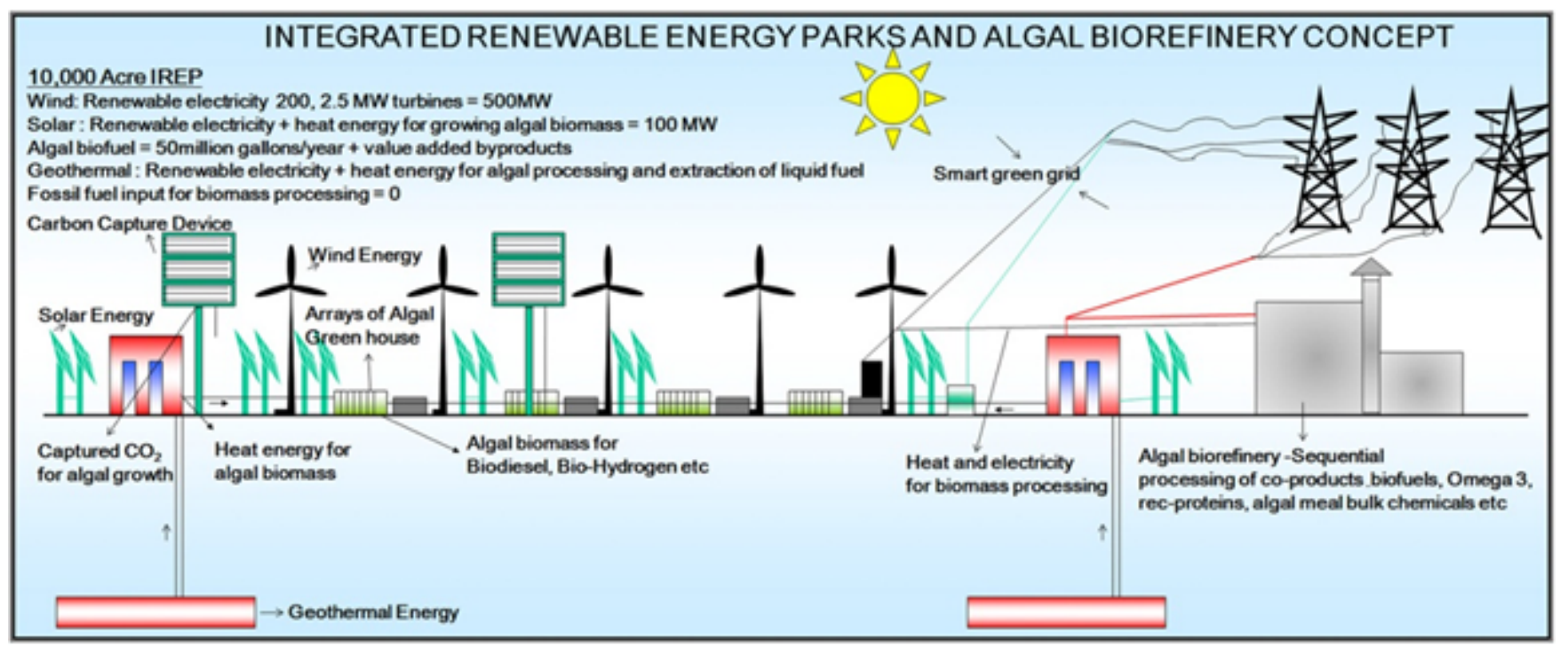

Figure 9: Integrated renewable energy and an Algal Biorefinery concept: a framework for the production of biofuel and high-value products with zero net carbon emissions (from Subhadra and Edwards [45].

The four pathways follow various nutrient sources (e.g., virgin commercial $\mathrm{CO}_{2}, \mathrm{CO}_{2}$ from a coal-fired power plant, compressed $\mathrm{CO}_{2}$ from flue gas, commercial fertilizers, and wastewater supplementation).

The authors found that algae-to-energy systems depend on the combination of cultivation and conversion processes used. They concluded that the conversion pathways involving direct combustion for the production of bioelectricity generally outperformed systems involving anaerobic digestion and biodiesel production. They ranked the four pathways as $\mathrm{D}>\mathrm{A}>\mathrm{C}>\mathrm{B}$ in terms of energy return on investment.

The authors found an algae bioelectricity (D) generation of $1,402,689 \mathrm{MJ} / \mathrm{km}$ and algae biodiesel + bioelectricity (C) generation of $1,110 \mathrm{MJ} / \mathrm{km}$. These algae-to-energy systems generate 4 and 15 times as VKT per hectare as switch grass or canola, respectively [47].

Subhadra and Edwards [48] analyzed the water footprint of two simulated algal biorefineries for the production of biodiesel, algal meal, and omega- 3 fatty acids. The authors highlighted the advantages of multiproducts to attain a high operational profit with a clear return on investment. The energy return of algal biodiesel for different scenarios ranged between 0.016-0.042 MJ.

Park, et al. [49,50] also studied algae which are grown as a byproduct of High-Rate Algal Ponds (HRAPs) operated for wastewater treatment. In addition to significantly better economics, algal biofuel production from wastewater treatment HRAPs has a much smaller environmental footprint compared to commercial algal production HRAPs which consume freshwater and fertilizers.

\section{Conclusions}

Biomass, as a renewable source, is attracting worldwide attention to satisfy the so called bioeconomy demand. Microalgae could be the appropriate feedstock as they did not compete with food and feed production, in terms of either land or water. Furthermore, microalgae remove/recycle nutrients from wastewater and flue-gases providing additional environmental benefits.
Due to their efficient sunlight utilization, microalgae are projected as living-cell factories with simple growth requirements. Their potential for energy and value-added products production is widely recognized.

Nevertheless, to be economically sustainable the tiny microalgae should supply a huge biorefinery. Technical advances combined with the several advantages such as $\mathrm{CO}_{2}$ capture, wastewater bioremediation and the extraction of value added-products will greatly increase algal bioproduct profitability.

The versatility and the huge potential of the tiny microalgae could support a microalgae biorefinery and microalgae-based bioeconomy, opening up a huge increase of opportunities in the global algae business.

\section{Acknowledgements}

The author would like to thank all the collaborators and co-authors of the al manuscripts mentioned in this paper, and Stephanie Seddon-Brown for English proof reading of this manuscript.

\section{References}

1. Shibata S, Natori Y, Nishihara T, Tomisaka K, Matsumoto K, et al. (2003) Antioxidant and anti-cataract effects of Chlorella on rats with streptozotocininduced diabetes. J Nutr Sci Vitaminol 49: 334-339.

2. Shibata S, Sansawa H (2006) Preventive effects of heterotrophically cultured Chlorella regularis on lifestyle-associated diseases. Annu Rep Yakult Central Inst Microbiol Res 26: 63-72.

3. Shibata S, Hayakawa K, Egashira Y, Sanada H (2007) Hypocholesterolemic mechanism of Chlorella: Chlorella and its indigestible fraction enhance hepatic cholesterol catabolism through up-regulation of cholesterol 7alpha-hydroxylase in rats. Biosci Biotechnol Biochem 71: 916-925.

4. Burja AM, Banaigs B, Abou-Mansour EB, Wright PC (2001) Marine cyanobacteria - a prolific source of natural products. Tetrahedron 57: 9347 9377.

5. Singh S, Kate BN, Banerjee UC (2005) Bioactive compounds from cyanobacteria and microalgae: an overview. Crit Rev Biotechnol 25: 73-95.

6. Yamaguchi K (1996) Recent advances in microalgal bioscience in Japan, with special reference to utilization of biomass and metabolites: A review. J Appl Phycol 8: 487-502.

7. Nuño K, Villarruel-López A, Puebla-Pérez AM, Romero-Velarde E, PueblaMora AG, et al. (2013) Effects of the marine microalgae Isochrysis galbana and Nannochloropsis oculata in diabetic rats. J Funct Foods 5: 106-115. 
8. Gerster H (1993) Anticarcinogenic Effect of Common Carotenoids. Int J Vitam Nutr Res 63: 93-121.

9. Willett WC (1994) Micronutrients and Cancer Risk. Am J Clin Nutr 59: 1162 1165

10. Lupulescu A (1994) The role of vitamin-A, vitamin-beta-carotene, vitamin-E and vitamin-C in cancer cell biology. Int J Vitam Nutr Res 64: 3-14.

11. Tanaka T, Shnimizu M, Moriwaki H (2012) Cancer Chemoprevention by Carotenoids. Molecules 17: 3202-3242.

12. Kohlmeier L, Hastings SB (1995) Epidemiologic Evidence of a Role of Carotenoids in Cardiovascular-Disease Prevention. Am J Clin Nutr 62 1370S-1376S

13. Giordano P, Scicchitano P, Locorotondo M, Mandurino C, Ricci G, et al. (2012) Carotenoids and Cardiovascular Risk. Curr Pharm Des 18: 5577-5589.

14. Snodderly DM (1995) Evidence for Protection against Age-Related Macular Degeneration by Carotenoids and Antioxidant Vitamins. Am J Clin Nutr 62: 1448S-1461S.

15. Weikel KA, Chiu CJ, Taylor A (2012) Nutritional modulation of age-related macular degeneration. Mol Aspects Med 33: 318-375.

16. Meydani SN, Wu DY, Santos MS, Hayek MG (1995) Antioxidants and ImmuneResponse in Aged Persons - Overview of Present Evidence. Am J Clin Nutr 62: 1462S-1476S.

17. Park JS, Chyun JH, Kim YK, Line LL, Chew BP (2010) Astaxanthin decreased oxidative stress and inflammation and enhanced immune response in humans. Nutr Metab (Lond) 7: 18

18. Matos CT, Gouveia L, Morais AR, Reis A, Bogel-Lukasik R (2013) Green metrics evaluation of isoprene production by microalgae and bacteria. Green Chem 15: 2854-2864

19. Painter TJ (1993) Carbohydrate polymers in desert reclamation. The potential of microalgal biofertilizers. Carbohyd Polym 20: 77-86.

20. Dey K (2011) Production of Biofertilizer (Anabaena and Nostoc) using $\mathrm{CO}_{2}$. Presentation on Roll: DURJ BT No.2011/2. Regn.No: 660.

21. Sahu D, Priyadarshani I, Rath B (2012) Cyanobacteria - as potential biofertilizer. CIBTech Journal Microbiol 1: 20-26.

22. Gouveia L, Oliveira C (2009) Microalgae as a raw material for biofuels production. J Ind Microbiol Biotechnol 36: 269-274.

23. Miranda JR, Passarinho PC, Gouveia L (2012) Bioethanol production from Scenedesmus obliquus sugars: the influence of photobioreactors and culture conditions on biomass production. Appl Microbiol Biotechnol 96: 555-564.

24. Marques AE, Barbosa TA, Jotta J, Tamagnini P, Gouveia L (2011) Biohydrogen production by Anabaena sp. PCC 7120 wild-type and mutants under different conditions: Light, Nickel and $\mathrm{CO}_{2}$. Biomass and Bioenergy 35: 4426-4434.

25. Ferreira AF, Ortigueira J, Alves L, Gouveia L, Moura P, et al. (2013a) Energy requirement and $\mathrm{CO}_{2}$ emissions of bioH $\mathrm{H}_{2}$ production from microalgal biomass. Biomass \& Bioenergy 49: 249-259.

26. Batista AP, Moura P, Marques PASS, Ortigueira J, Alves L, et al. (2014) Scenedesmus obliquus as a feedstock for bio-hydrogen production by Enterobacter aerogenes and Clostridium butyricum by dark fermentation. Fuel 117: 537-543.

27. Wijffels RH, Barbosa MJ, Eppink MHM (2010) Microalgae for bulk chemicals and biofuels. Biofuels Bioprod Bioref 4: 287-295.

28. Vanthoor-Koopmans M, Wijffels RH, Barbosa MJ, Eppink MHM (2013) Biorefinery of microalgae for food and fuel. Bioresour Technol 135: 142-149.

29. Brennan L, Owende P (2010) Biofuels from microalgae - A review of technologies for production, processing, and extractions of biofuels and coproducts. Ren Sustain Energy Rev 14: 557-577.

30. da Silva TL, Gouveia L, Reis A (2014) Integrated microbial processes for biofuels and high added value products: the way to improve the cost effectiveness of biofuel production. Appl Microbiol Biotechnol. doi:10.1007/s00253-013-5389-5.

Citation: Gouveia L (2014) From Tiny Microalgae to Huge Biorefineries. Oceanography 2: 120 . doi:10.4172/2332-2632.1000120
31. Nobre BP, Villalobos F, Barragán BE, Oliveira AC, Batista AP, et al. (2013) A biorefinery from Nannochloropsis sp. microalga - Extraction of oils and pigments. Production of biohydrogen from the leftover biomass. Bioresour Technol 135: 128-136.

32. Ferreira AF, Marques AC, Batista AP, Marques PASS, Gouveia L, et al. (2012) Biological hydrogen production by Anabaena sp. - yield, energy and $\mathrm{CO}$ analysis including fermentative biomass recovery. Int $\mathrm{J}$ Hydrogen Energ 37 : $179-190$

33. Collet P, Hélias A, Lardon L, Ras M, Goy RA, et al. (2011) Lifecycle assessment of microalgae culture coupled to biogas production. Bioresour Technol 102: 207-214.

34. Ehimen EA, Sun ZF, Carrington CG, Birch EJ, Eaton-Rye JJ (2011) Anaerobic digestion of microalgae residues resulting from the biodiesel production process. Appl Energ 88: 3454-3463

35. Gouveia L, Neves C, Sebastião D, Nobre BP, Matos CT (2014) Effect of light on the production of bioelectricity and pigments by a Photosynthetic Alga Microbia Fuel Cell. Bioresour Technol 154: 171-177.

36. Powel EE, Hill GA (2009) Economic assessment of an integrated bioethanolbiodiesel-microbial fuel cell facility utilizing yeast and photosynthetic algae. Chem Eng Res Design 87: 1340-1348.

37. Campenni' L, Nobre BP, Santos CA, Oliveira AC, Aires-Barros AR, et al (2013) Carotenoids and lipids production of autotrophic microalga Chlorella protothecoides under nutritional, salinity and luminosity stress conditions. App Microbiol Biotechnol 97: 1383-1393.

38. EN 14214 (2008) Automotive fuels_fatty acid methyl esters (FAME) for diesel engines-requirements and test methods.

39. Mussgnug JH, Klassen V, Schlüter A, Kruse O (2010) Microalgae as substrates for fermentative biogas production in a combined biorefinery concept. $J$ Biotechnol 150: 51-56.

40. Sialve B, Bernet N, Bernard O (2009) Anaerobic digestion of microalgae as a necessary step to make microalgal biodiesel sustainable. Biotechnol Adv 27 : 409-416.

41. Kim AL, Lee OK, Seong DH, Lee GG, Jung YT, et al. (2013) Chemoenzymatic saccharification and bioethanol fermentation of lipid-extracted residual biomass of the microalga Dunaliella tertiolecta. Bioresour Technol 132: 197-201.

42. Olguín EJ (2012) Dual purpose microalgae-bacteria-based systems that treat wastewater and produce biodiesel and chemical products within a biorefinery. Biotechnol Adv 30: 1031-1046.

43. Pacheco R, Ferreira AF, Pinto T, Nobre BP, Loureiro D, et al. (2014) Life Cycle Assessment of a Spirogyra sp. biorefinery for the production of pigments, hydrogen and leftovers energy valorisation. Applied Energy.

44. Mostafa SSM, Shalaby EA, Mahmoud GI (2012) Cultivating microalgae in domestic wastewater for biodiesel production. Nat Sci Biol 4: 56-65.

45. Subhadra B, Edwards M (2010) Algal biofuel production using integrated renewable energy park approach in United States. Energ Policy 38: 4897-4902.

46. Subhadra BG (2010) Sustainability of algal biofuel production using integrated renewable energy park (IREP) and algal biorefinery approach. Energy Policy 38: 5892-5901.

47. Clarens AF, Nassau H, Resurreccion EP, White MA Colosi LM (2011) Environmental Impacts of Algae-Derived Biodiesel and Bioelectricity for Transportation. Environ Sci Technol 45: 7554-7560.

48. Subhadra B, Edwards B (2011) Coproduct market analysis and water footprin of simulated commercial algal biorefineries. Appl Energ 88: 3515-3523.

49. Park JBK, Craggs RJ, Shilton AN (2011) Wastewater treatment high rate algal ponds for biofuel production. Bioresour Technol 102: 35-42.

50. Ferreira AF, Ribeiro L, Batista AP, Marques PASS, Nobre BP, et al. (2013b) A Biorefinery from Nannochloropsis sp. microalga - Energy and $\mathrm{CO}_{2}$ emission and economic analyses. Bioresour Technol 138: 235-244.

This article was originally published in a special issue, Seaweeds, Micro- and Macro-algae handled by Editor. Dr. Jeffrey Craig Bailey, University of North Carolina, USA 